\title{
A Decision Optimization Model for Leased Manufacturing Equipment with Warranty under Forecasting Production/Maintenance Problem
}

\author{
Zied Hajej, ${ }^{1,2}$ Nidhal Rezg, ${ }^{1,2}$ and Ali Gharbi ${ }^{3}$ \\ ${ }^{1}$ Laboratoire de Génie Industriel, de Production et de Maintenance, Université de Lorraine, 57045 Metz, France \\ ${ }^{2}$ ICN Business School, 13 rue Michel Ney, 54000 Metz-Nancy, France \\ ${ }^{3}$ Automated Production Engineering Department, Production System Design and Control Laboratory, \\ Éecole de Technologie Supérieure, University of Québec, 1100 Notre Dame Street West, Montreal, QC, Canada H3C 1K3
}

Correspondence should be addressed to Zied Hajej; zied.hajej@univ-lorraine.fr

Received 2 July 2014; Revised 24 September 2014; Accepted 24 September 2014

Academic Editor: Shaomin Wu

Copyright $\odot 2015$ Zied Hajej et al. This is an open access article distributed under the Creative Commons Attribution License, which permits unrestricted use, distribution, and reproduction in any medium, provided the original work is properly cited.

\begin{abstract}
Due to the expensive production equipment, many manufacturers usually lease production equipment with a warranty period during a finite leasing horizon, rather than purchasing them. The lease contract contains the possibility of obtaining an extended warranty for a given additional cost. In this paper, based on the forecasting production/maintenance optimization problem, we develop a mathematical model to study the lease contract with basic and extended warranty based on win-win relationship between the lessee and the lessor. The influence of the production rates in the equipment degradation consequently on the total cost by each side during the finite leasing horizon is stated in order to determine a theoretical condition under which a compromise-pricing zone exists under different possibilities of maintenance policies.
\end{abstract}

\section{Introduction}

Due to the rapid advances in technology, the technological obsolescence appeared in the market at a quick rate with the new and better equipment. On the other hand, the owning cost of this new equipment became very high. Due to these different reasons, more and more industries started leasing equipment rather than owning them. The maintenance actions in leasing contract are considered the most important element negotiable between the manufacturer and the consumer. Prior to the onset of leasing aspect, most businesses owned the equipment and the different preventive and corrective maintenance actions were approved internally. This began to change with the progress complexity of equipment with specialist services and their uneconomical maintenance actions made in-house. On the other hand, most manufacturers considered the maintenance as a no basic activity which is why they focus only on the principal activities, which are considered as the basic of the business. In this context, the notion of warranty is attached to the leasing concept since the leasing contract contains the warranty for the maintenance service. In this case, we can consider the warranty as a selling argument to attract and win more customers concerning the point of view of the lessor. From the customers' point of view, warranty means reducing the cost of repairs or replacement of the defective equipment during the warranty period.

The maintenance of leased equipment offered by the equipment owner is generally quantified in a lease contract provided by the lessor to the lessee (Murthy and Asgharizadeh [1]). Concerning the maintenance strategy for leased equipment, some research works treated this type of problem with numerous preventive maintenance policies, which have been proposed and studied under various situations, such as perfect or imperfect maintenance. Yeh and Chang [2] determine the optimal number of lease periods and define the maintenance strategy for leased equipment that is based on a minimal repair to restore the equipment to an operating condition when the leased equipment fails and an 
imperfect preventive maintenance is done to avoid failures, when the age of the equipment reaches a certain threshold value. In the same context, Jaturonnatee et al. [3] proposed a method of failure-rate reduction, in which the failure rate of equipment is reduced after each preventive maintenance action, to solve the optimal maintenance policy of leased equipment under periodical preventive maintenance actions.

Concerning the warranty periods of the production machines, in numerous cases, due to the complexity of maintenance actions for various machines, the consumers prefer to buy a supplementary period of warranty by covering an extra cost in order to avoid problems of production/maintenance cost increase and the production system perturbation. In this context, Berke and Zaino [4] treated two types of warranties contracts that were intended to assure the consumer that the product would perform its planned functions under specific conditions and periods of time. The first type defined a combination policy that proposed an initial free-replacement warranty and from a certain period the replacement item's cost is calculated on a sliding scale. The other was the fleet warranty, which guarantees a purchaser of a large quantity of wanted items an average field performance. Remaining with warranty and maintenance aspect, Kim et al. [5] defined the relation between the warranty and preventive maintenance by showing the impact of PM over warranty period on the cost of warranty service. Yun et al. [6] proposed two new warranty servicing strategies, concerning imperfect and minimal repairs. In the first strategy, they involve a functional optimization to determine the optimal improvement in reliability, when an imperfect repair is carried over the warranty period and depends on the age of the item. In the second strategy, they include only a parameter optimization to determine the optimal reliability improvement that does not depend on the age.

On the other hand, there are other types of warranties applied to nonrepairable products; we can cite the renewing free-replacement warranty (RFRW) in which in the case of product failure under warranty period it is replaced by a new one with a full warranty. Chien [7] investigated analytically the impacts of the RFRW on the optimal age-replacement policy for a repairable product with a general failure model. They presented a general model that contains two types of failure when the product fails. In type 1, the failure (minor failure) is removed by a minimal repair, whereas in type 2 of failure (catastrophic failure) it is removed only by a replacement. Chien [8] presented a new warranty strategy based on an age-replacement policy for products, which combines a fully renewable free-replacement with a pro rata warranty policy (RFRW/RPRW policy). They developed a cost model from the user/buyer and discussed special cases of the model, in order to determine the corresponding local optimal replacement age by minimizing the long run expected cost rate.

The majority of the researches concerning the warranty problems consider a fixed warranty period while the dynamic warranty period or otherwise the extended warranty period, especially in the lease contract, helps the lessor to keep contact with clients after the end of warranty period. Extended warranty helps the customer to continue with the same maintenance service of well-known equipment. In this context, Bouguerra et al. [9] developed a mathematical model to study the opportunity provided by the extended warranty for the consumer and manufacturer and proposed a strategy of a long guarantee plan of the preventive maintenance for the systems subjected to the random troubleshooting. This strategy considers diverse options for maintenance policies during the following periods: basic guarantee period, extended guarantee period, and postguarantee period.

$\mathrm{Wu}$ and Longhurst [10] showed the influence of both the length of warranty period and replacement time on the life cycle cost of equipment. They formulated the expected life cycle cost considering the opportunity-based age-replacement policy with minimal repair for an extended warranty and maintenance. They also proved the conditions for the existence of optimal solutions for both the length of the extended warranty period and the design life for special cases.

Recently, another type of problem that deals with leasing/warranty problem is treated by Hajej et al. [11]; they handled the optimization problem of production and maintenance policies for leased equipment under a lease contract with warranty periods. A mathematical model of the total production and maintenance cost is developed and an optimal production planning as well as the corresponding optimal maintenance strategy is derived by choosing the optimal warranty periods for the lessee in order to minimize the total cost.

Motivated by our work in Hajej et al. [11], we can consider this work is a continuation of our work in Hajej et al. [11] where we determine the most optimal basic warranty periods for the lessee. This study shows that it has novelty and originality relative to this type of problem, which considers a mathematical model to study the opportunity provided to extend the warranty for the lessee. Based on a forecasting production and maintenance problem for leasing machine, we will determine the total cost of leasing machine for each side in order to determine, for any given situation, zone of possible compromise yielding a win-win relationship with respect to the extended warranty cost. The zone of compromise is characterized by the maximum extra cost the lessee should pay for the extended warranty and the minimum price at which the lessor should sell it. Indeed, we have shown the influence of production rates as well as the maintenance actions of the manufacturing machine over the warranty and the extended warranty period on the warranty servicing cost.

This study proposes a new idea of production and maintenance coupling in the leasing aspect with warranty. This study shows that it has novelty and originality relative to this type of problem, which considers and proposes a new maintenance strategy for leasing contract with extended warranty based on win-win relationship between the lessee and the lessor. This originality is characterised by the influence of the production variation rates on the machine degradation degree that is new in the literature charactering by analytical study that shows the evolution of the machine failure rate according to its use respecting at the same time the continuity of the equipment reliability from a period to another. Secondly, in 
our opinion, no analytical or numerical way has been stated in the literature, which leads to a decision framework to the lessee and/or to the lessor making the identification of pricing zones of the extended warranty acceptable for both sides.

The remainder part of this paper is organized as follows. Section 2 states the problem. Section 3 presents and develops the mathematical model concerning the forecasting production problem and the different policies of maintenance considering the influence of production rates on the leasing machine degradation. Section 4 presents a numerical example illustrating our approach followed by a variability study showing the impact of variation of preventive maintenance costs on our model. Finally, the conclusion is given in Section 5 .

\section{Problem Description}

2.1. Problem Statement. In this work, we are considering the problem of forecasting production and maintenance problem for leasing machine with warranty periods. The idea of our problem is to define a new aspect in the leasing contract. Generally, several pieces of equipment are leased with a warranty period but there are leasing contracts that propose to the lessee (who leases the equipment) the possibility of purchasing an additional period of warranty which will start at the end of the basic warranty period by adding additional costs. Hence, the lessee has to decide whether to buy or not the extended warranty period and what the price of the extended warranty is. It is a difficult decision for each side. The lessee does not know if the extra cost (the price of the extended warranty) of the leasing equipment would exceed the potential repairs cost that would be borne by him in case he does not take the extended warranty. On the other hand, for the lessor not to lose, the price of extended warranty should be higher than the cost of claims servicing borne (maintenance actions) by him during the additional warranty period.

We will answer all these questions by proposing a forecasting model in whichthe lessee leases a manufacturing machine. The equipment is leased for a multihorizon $L \cdot \Delta t$ (we assumed that the production horizon is portioned equally to periods with a length equal to $\Delta t$ ) with a warranty period $X$. $\Delta t$. We suppose that leasing production machine is designed in order to produce only one type of product in a manufacturing system composed also by a manufacturing store, where the customer receives his demand over the leasing finite horizon $L$. Moreover, for the forecasting problem, we assume that the satisfaction of the demand is under a given inventory service level $\alpha$ and the fluctuation of the demand is a normal distribution with mean and variance given, respectively, by $\widehat{d}$ and $\sigma_{d}$ (Figure 1).

The considered leased machine is subject to the random failures. Its failure rate $\lambda(t)$ increases with both time and production rate. An influence of the production rate variation on the equipment degradation and hence on the average number of failures is considered.

The leasing contract includes the machine under warranty period $X$ with the possibility of being extended until

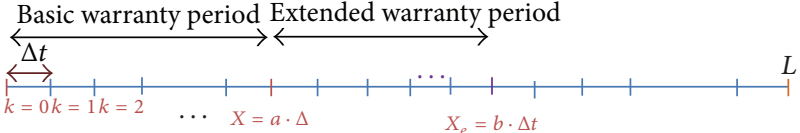

FIGURE 1: Life cycle of leasing machine with warranty and extended warranty periods.

instant $X_{e}$ for an additional cost $C_{X}$ paid by the lessee when leasing the machine. Namely, all maintenance actions during the basic and extended warranty periods are supported by the lessor at no cost to the lessee. For the rest of the leasing periods, the equipment is not under warranty and the maintenance actions are under the responsibility of the lessee.

The maintenance actions are considered the well-known preventive maintenance policy with minimal repair at failure with negligible duration keeping the system failure rate nearly the same. The role of maintenance is to increase the availability of machine reducing the maintenance costs in order to ensure the production plan on the leasing horizon $L$.

According to the forecasting problem as well as the optimal production plan of leasing machine obtained, our objective is to develop a mathematical model to study the opportunity provided by the extended warranty from the lessee and the lessor perspectives. We will express the total expected cost incurred by each side during the product's life cycle in order to determine, for any given situation, the maximum extra cost the lessee should pay for the extended warranty and the minimum price at which the lessor should sell it. Taking into account the influence of preventive maintenance actions performing on the leasing machine during the basic and extended warranty periods, we are considering different cases of maintenance strategies approved during the life cycle of leased machine.

\section{Mathematical Model}

\subsection{Forecast Production Plan}

(i) Stochastic Production Model. Based on the approach proposed by Zied et al. [12] and Hajej et al. [11], the production planning problem is formulated as a quadratic model whose decision variables include production rates and inventory levels. The purpose of this section is to develop a mathematical model that will allow us to determine the optimal production plan $U^{*}\left(U^{*}=u(k)^{*}\right.$ and $\left.k=1, \ldots, L-1\right)$ during the leasing horizon $L$.

Formally, the stochastic production model is defined as follows:

$$
\begin{aligned}
& \text { Minimize } Z=\sum_{k=0}^{L} f_{k}\left(U_{k}, S_{k}\right)=C_{s} \cdot E\left\{S_{L}^{2}\right\} \\
& +\sum_{k=0}^{L} C_{s} \cdot E\left\{S_{k}^{2}\right\}+C_{\mathrm{pr}} \cdot U_{k}^{2}
\end{aligned}
$$


(i) inventory balance equation constraints

$$
S_{k+1}=S_{k}+U_{k}-d_{k} \quad k \in\{0,1, \ldots, L-1\} ;
$$

(ii) service level requirement for each period

$$
\operatorname{Prob}\left[S_{k+1} \geq 0\right] \geq \alpha \quad k \in\{0,1, \ldots, L-1\} ;
$$

(iii) capacity constraints

$$
0 \leq U_{k} \leq U^{\max } \quad k \in\{0,1, \ldots, L-1\} .
$$

(ii) Deterministic Production Model. An approach that transforms the stochastic problem into a deterministic equivalent is necessary. This deterministic problem maintains the main properties of the original problem.

The quadratic total expected cost of production and inventory over the leasing periods $L$ can be expressed then as follows:

$$
\begin{aligned}
Z(u)= & C_{s} \times\left(\widehat{S}_{L}^{2}\right)+\sum_{k=0}^{L-1} C_{s} \cdot \widehat{S}_{k}^{2}+C_{\mathrm{pr}} \times u_{k}^{2} \\
& +C_{s} \times \sigma_{d}^{2} \times \frac{L(L+1)}{2}
\end{aligned}
$$

with the following.

(i) It has mean variables

$$
E\left\{S_{k}\right\}=\widehat{S}_{k}, \quad E\left\{u_{k}\right\}=u_{k}
$$

and variance variables $V_{u_{k}}=0$. (Variable $u_{k}$ is deterministic.)

(ii) The inventory balance (2) can be reformulated as

$$
\widehat{S}_{k+1}=\widehat{S}_{k}+u_{k}-\widehat{d}_{k} \quad k=0,1, \ldots, L-1 .
$$

Proof. See the Appendix.

(iii) Service Level Constraint. As another step to transform the stochastic problem into an equivalent deterministic one, we consider a service level constraint in a deterministic form by determining a minimum cumulative production quantity depending on the service level requirements.

For $k \in\left\{0,1, \ldots, h_{i}-1\right\}$ we have

$$
\operatorname{Prob}\left(S_{k+1} \geq 0\right) \geq \alpha \Longrightarrow\left(U_{k} \geq V_{d, k} \cdot \varphi_{d, k}^{-1}(\alpha)+\widehat{d}_{k}-\widehat{S}_{k}\right)
$$

where $\varphi_{d, k}$ : cumulative Gaussian distribution function with mean $\widehat{d}_{k}$ and finite variance $\operatorname{Var}\left(d_{k}\right)=V_{d, k} \geq 0$ and $V_{d, k}$ : variance of demand $d$ at period $k$.

Proof. See the Appendix.
3.2. Maintenance Policy. Based on the work of $\mathrm{Wu}$ and Longhurst [10], the maintenance strategy considers the manufacturing system's degradation according to the production rate during the leasing horizon $L$. The correlation of the degradation of the machine production rates is manifested by an increased failure rate according to both time and production rate.

We assume that, during the machine life cycle, perfect preventive maintenance or replacement is performed periodically at times $i \cdot T, i=0,1, \ldots, N_{j}$ (with $N_{j}$ number of preventive maintenance over each interval during the leasing periods: basic warranty, extended warranty, and postwarranty and $T$ preventive maintenance action interval) following which the unit is as good as new.

The evolution of the machine failure rate according to its use (which is in our case the production rate for each period) respecting at the same time the continuity of the equipment reliability from a period to another is presented by an analytical equation.

The failure rate in the interval $k$ is expressed as follows:

$$
\lambda_{k}(t)=\lambda_{k-1}(\Delta t)+\frac{U_{k}}{U_{\max }} \cdot \lambda_{n}(t) \quad \forall t \in[0, \Delta t]
$$

with

$$
\lambda_{k=0}=\lambda_{0}, \quad \Delta \lambda_{k}(t)=\frac{U_{k}}{U_{\max }} \cdot \lambda_{n}(t),
$$

where $\lambda_{n}(t)$ is the nominal failure rate corresponding to the maximal production rate.

Allowing maintenance strategy, we can define the different numbers of preventive maintenance over each interval during the leasing periods given by the following:

$N_{1}$ : number of PM actions during the basic warranty periods $[0, X)$ with a value equal to $\operatorname{In}(X / T)$;

$\mathrm{N}_{2}$ : number of PM actions during the leasing periods $[0, L)$ with a value equal to $\operatorname{In}(L / T)$;

$N_{3}$ : number of PM actions between the end of basic warranty and the end of the leasing periods $[X, L)$ with a value equal to $\operatorname{In}((L-X) / T)$;

$N_{4}$ : number of PM actions during the basic and extended warranty periods $\left[0, X_{e}\right)$ with a value equal to $\operatorname{In}\left(X_{e} / T\right)$;

$N_{5}$ : number of PM actions during the extended warranty $\left[X, X_{e}\right)$ with a value equal to $\operatorname{In}\left(\left(X_{e}-X\right) / T\right)$;

$N_{6}$ : number of PM actions between the end of extended warranty periods and the end of leasing periods $\left[X_{e}, L\right)$ with a value equal to $\operatorname{In}\left(\left(L-X_{e}\right) / T\right)$,

with In: integer part of a real number.

We express below the analytic expression of the total maintenance cost incurred by each side during the leasing period of machine where $\varphi_{M}\left(U, N_{i}\right)$ corresponds to the expected number of failures that occur during the different intervals defined above, considering the production rate in each production period $\Delta t$ :

$$
\xi\left(U, N_{i}\right)=C_{\mathrm{pm}} \times\left(N_{i}-1\right)+C_{\mathrm{cm}} \times \varphi_{M}\left(U, N_{i}\right) .
$$


Let In denote the integer part of $(\cdot)$. Then the average number according to failure rate defined above is

$$
\begin{aligned}
& \varphi_{M}\left(U, N_{i}\right) \\
&=\sum_{j=0}^{N_{i}-1}\left[\sum_{i=\operatorname{In}(j \times(T / \Delta t))+1}^{\operatorname{In}((j+1) \times(T / \Delta t))} \int_{0}^{\Delta t} \lambda_{i}(t)\right. \\
&+\int_{0}^{(j+1) \times T-\operatorname{In}((j+1) \times(T / \Delta t)) \times \Delta t} \lambda_{\operatorname{In}((j+1) \times(T / \Delta t))+1}(t) d t \\
&+\int_{(j+1) \times T}^{(\operatorname{In}((j+1) \times(T / \Delta t))+1) \times \Delta t} \frac{((\operatorname{In}((j+1) \times(T / \Delta t))+1))}{U_{\max }} \\
&\left.\quad \times \lambda_{n}(t) d t\right] .
\end{aligned}
$$

Using the total cost, we can determine the zone of possible compromise yielding a win-win relationship between the lessor and the lessee characterized by the maximum additional cost for the lessee who should pay for the extended warranty and the minimum price at which the lessor should sell it. There are different cases of maintenance strategy adopted during the leasing horizon taking into account the impact of preventive maintenance on the warranty servicing cost.

The following maintenance policies will be considered for lessor and lessee sides.

(i) Policy I. Periodic PM actions during the post-basic warranty period: for this policy we consider the following possibility.

(a) Policy I-1. PM actions are performed during the extended warranty $\left[X, X_{e}\right)$ at times $i \cdot T, i=$ $0,1, \ldots, N_{5}$, supported by the lessor and PM actions are performed from the end of extended warranty $\left[X_{e}, L\right)$ at times $i \cdot T, i=0,1, \ldots, N_{6}$, supported by the lessee (Figure 2 ).

(ii) Policy II. Periodic PM actions during the warranty period: for this case we consider two different possibilities.

(a) Policy II-1. PM actions are performed only during the basic warranty period $[0, X)$ at times $i \cdot T, i=0,1, \ldots, N_{1}$, supported by the lessor.

(b) Policy II-2. PM actions are performed during both the basic and the extended warranty periods $\left[0, X_{e}\right)$ at times $i \cdot T, i=0,1, \ldots, N_{4}$, supported by the lessor.

3.3. Maximum Additional Cost Paid for Extended Warranty: Lessee Side. The subsection determines the maximum additional cost that the lessee should pay for the extended warranty during the leasing periods. The comparison of the total maintenance costs acquired to the lessee between the case in which he does not take the extended warranty period

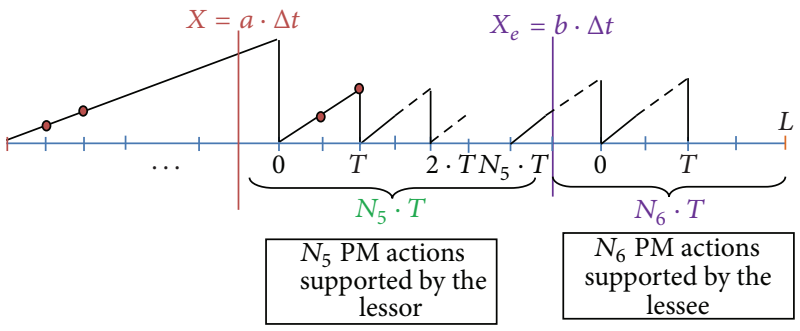

FIgURe 2: Evolution of failure rate for Policy I-1.

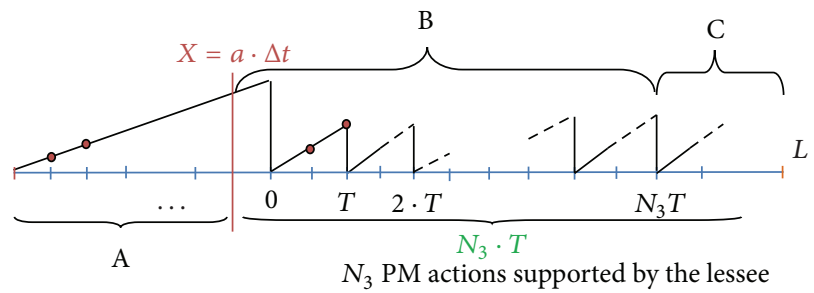

FIgURE 3: Average number of failures for the case in which he does not take the extended warranty period.

and the case in which he takes it is necessary to determine the cost of the extended warranty period paid by the lessee. In this case, side of lessee, we state for each maintenance policy that the best situation for buying the extended warranty period would be least cost for the lessee. This is the best situation obtained, where the total maintenance cost incurred to him in the case of purchase of extended warranty would be lower than in the case he does not take it.

We assume that $\xi_{c P n}$ and $\xi_{c P y}$ are the total maintenance costs acquired to the lessee for maintenance policy $(P)$, respectively, for the case in which he does not take the extended warranty period $(n)$ and the case in which he takes it $(y)$.

We recall that $N_{1}=X / T ; N_{3}=(L-X) / T ; N_{5}=\left(X_{e}-\right.$ $X) / T ; N_{6}=\left(L-X_{e}\right) / T ; X=a \cdot \Delta t ; X_{e}=a_{1} \cdot \Delta t ; \Delta t$ is length of production period.

(i) Policy I (see Figures 3 and 4).

(a) Policy I-1. Consider

$$
\begin{aligned}
\xi_{c I-1 y}+\xi_{c X} & \leq \xi_{c I-1 n} \\
\Longrightarrow & \xi_{c X} \leq \xi_{c I-1 n}-\xi_{c I-1 y} \Longrightarrow \xi_{c X} \leq A_{c I}
\end{aligned}
$$

where

$$
\begin{aligned}
\xi_{c I-1 n} & \\
=C_{\mathrm{cm}} \times & {\left[\sum_{i=1}^{\operatorname{In}(X / \Delta t)} \int_{0}^{\Delta t} \lambda_{i}(t) d t\right.} \\
& +\sum_{j=0}^{N_{3}-1} \sum_{i=\operatorname{In}(j \cdot(T / \Delta t))+(X / \Delta t)+1}^{\operatorname{In}((j+1) \cdot(T / \Delta t))+(X / \Delta t)} \int_{0}^{\Delta t} \lambda_{i}(t) d t
\end{aligned}
$$


6

Mathematical Problems in Engineering

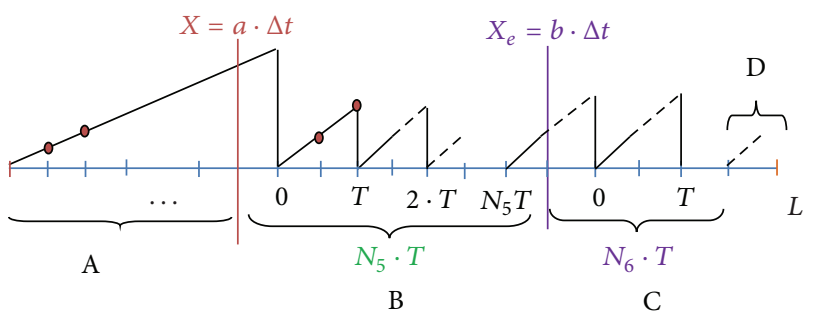

FIGURE 4: Average number of failures for the case in which he takes the extended warranty period.

$$
\begin{aligned}
& \left.+\sum_{i=\operatorname{In}\left(N_{3} \cdot(T / \Delta t)\right)+(X / \Delta t)+1}^{(L / \Delta t)} \int_{0}^{\Delta t} \lambda_{i}(t) d t\right] \\
& +N_{3} \times C_{\mathrm{pm}} \text {, } \\
& \xi_{c I-1 y} \\
& =C_{\mathrm{cm}} \times\left[\sum_{i=1}^{\operatorname{In}(X / \Delta t)} \int_{0}^{\Delta t} \lambda_{i}(t) d t\right. \\
& +\sum_{i=\operatorname{In}\left(N_{5} \cdot(T / \Delta t)\right)+(X / \Delta t)+1}^{\operatorname{In}\left(X_{e} / \Delta t\right)} \int_{0}^{\Delta t} \lambda_{i}(t) d t \\
& +\sum_{j=0}^{N_{6}-1} \sum_{i=\operatorname{In}(j \cdot(T / \Delta t))+\left(X_{e} / \Delta t\right)+1}^{\operatorname{In}((j+1) \cdot(T / \Delta t))+\left(X_{e} / \Delta t\right)} \int_{0}^{\Delta t} \lambda_{i}(t) d t \\
& \left.+\sum_{i=\operatorname{In}\left(N_{6} \cdot(T / \Delta t)\right)+\left(X_{e} / \Delta t\right)+1}^{(L / \Delta t)} \int_{0}^{\Delta t} \lambda_{i}(t) d t\right] \\
& +N_{6} \times C_{\mathrm{pm}} \text {, } \\
& A_{\text {cI }} \\
& =C_{\mathrm{cm}} \times\left[\sum_{j=0}^{N_{3}-1} \sum_{i=\operatorname{In}(j \cdot(T / \Delta t))+(X / \Delta t)+1}^{\operatorname{In}((j+1) \cdot(T / \Delta t))+(X / \Delta t)} \int_{0}^{\Delta t} \lambda_{i}(t) d t\right. \\
& +\sum_{i=\operatorname{In}\left(N_{3} \cdot(T / \Delta t)\right)+(X / \Delta t)+1}^{\operatorname{In}(L / \Delta t)} \int_{0}^{\Delta t} \lambda_{i}(t) d t \\
& -\sum_{i=\operatorname{In}\left(N_{5} \cdot(T / \Delta t)\right)+(X / \Delta t)+1}^{\operatorname{In}\left(X_{e} / \Delta t\right)} \int_{0}^{\Delta t} \lambda_{i}(t) d t \\
& -\sum_{j=0}^{N_{6}-1 \operatorname{In}((j+1) \cdot(T / \Delta t))+\left(X_{e} / \Delta t\right)} \sum_{i=\operatorname{In}(j \cdot(T / \Delta t))+\left(X_{e} / \Delta t\right)+1}^{\Delta t} \int_{0}^{\Delta t} \lambda_{i}(t) d t
\end{aligned}
$$

$$
\begin{aligned}
&\left.-\sum_{i=\operatorname{In}\left(N_{6} \cdot(T / \Delta t)\right)+\left(X_{e} / \Delta t\right)+1}^{\operatorname{In}(L / \Delta t)} \int_{0}^{\Delta t} \lambda_{i}(t) d t\right] \\
&+C_{\mathrm{pm}} \times\left(N_{3}-N_{6}\right) .
\end{aligned}
$$

(a) Policy II-1. Consider

$$
\begin{aligned}
& \xi_{c I I-1 y}+\xi_{c w} \leq \xi_{c I I-1 n} \\
& \longrightarrow \xi_{c X} \leq \xi_{c I I-1 n}-\xi_{c I I-1 y} \longrightarrow \xi_{c X} \leq B_{c 1} \\
& \xi_{c I I-1 n} \\
& =C_{\mathrm{cm}} \times\left[\sum_{i=\operatorname{In}\left(N_{1} \cdot(T / \Delta t)\right)+1}^{\operatorname{In}(X / \Delta t)} \int_{0}^{\Delta t} \lambda_{i}(t) d t\right. \\
& +\sum_{j=0}^{N_{3}-1} \sum_{i=\operatorname{In}(j \cdot(T / \Delta t))+(X / \Delta t)+1}^{\operatorname{In}((j+1) \cdot(T / \Delta t))+(X / \Delta t)} \int_{0}^{\Delta t} \lambda_{i}(t) d t \\
& \left.+\sum_{i=\operatorname{In}\left(N_{3} \cdot(T / \Delta t)\right)+(X / \Delta t)+1}^{\operatorname{In}(L / \Delta t)} \int_{0}^{\Delta t} \lambda_{i}(t) d t\right] \\
& +N_{3} \times C_{\mathrm{pm}} \text {, } \\
& \xi_{c I I-1 y} \\
& =C_{\mathrm{cm}} \times\left[\sum_{i=\operatorname{In}\left(N_{1} \cdot(T / \Delta t)\right)+1}^{\operatorname{In}(X / \Delta t)} \int_{0}^{\Delta t} \lambda_{i}(t) d t\right. \\
& +\sum_{i=(w / \Delta t)}^{\left(X_{e} / \Delta t\right)} \int_{0}^{\Delta t} \lambda_{i}(t) d t \\
& +\sum_{j=0}^{N_{6}-1} \sum_{i=\operatorname{In}(j \cdot(T / \Delta t))+\left(X_{e} / \Delta t\right)+1}^{\operatorname{In}((j+1) \cdot(T / \Delta t))+\left(X_{e} / \Delta t\right)} \int_{0}^{\Delta t} \lambda_{i}(t) d t \\
& \left.+\sum_{i=\operatorname{In}\left(N_{6} \cdot(T / \Delta t)\right)+\left(X_{e} / \Delta t\right)+1}^{\operatorname{In}(L / \Delta t)} \int_{0}^{\Delta t} \lambda_{i}(t) d t\right] \\
& +N_{6} \times C_{\mathrm{pm}} \text {, } \\
& B_{c 1} \\
& =C_{\mathrm{cm}} \times\left[\sum_{j=0}^{N_{3}-1} \sum_{i=\operatorname{In}(j \cdot(T / \Delta t))+(X / \Delta t)+1}^{\operatorname{In}((j+1) \cdot(T / \Delta t))+(X / \Delta t)} \int_{0}^{\Delta t} \lambda_{i}(t) d t\right.
\end{aligned}
$$




$$
\begin{gathered}
+\sum_{i=\operatorname{In}\left(N_{3} \cdot(T / \Delta t)\right)+(X / \Delta t)+1}^{\operatorname{In}(L / \Delta t)} \int_{0}^{\Delta t} \lambda_{i}(t) d t \\
-\sum_{i=\operatorname{In}(X / \Delta t)}^{\operatorname{In}\left(X_{e} / \Delta t\right)} \int_{0}^{\Delta t} \lambda_{i}(t) d t \\
-\sum_{j=0}^{N_{6}-1 \operatorname{In}((j+1) \cdot(T / \Delta t))+\left(X_{e} / \Delta t\right)} \sum_{i=\operatorname{In}(j \cdot(T / \Delta t))+\left(X_{e} / \Delta t\right)+1}^{\Delta t} \lambda_{i}(t) d t \\
\left.-\sum_{i=\operatorname{In}\left(N_{6} \cdot(T / \Delta t)\right)+\left(X_{e} / \Delta t\right)+1}^{\operatorname{In}(L / \Delta t)} \int_{0}^{\Delta t} \lambda_{i}(t) d t\right] \\
+C_{\mathrm{pm}} \times\left(N_{3}-N_{6}\right) .
\end{gathered}
$$

(b) Policy II-2. Consider

$$
\begin{aligned}
& \xi_{c I I-2 y}+\xi_{c X} \leq \xi_{c I I-2 n} \\
& \longrightarrow \xi_{c X} \leq \xi_{c I I-2 n}-\xi_{c I I-2 y} \longrightarrow \xi_{c X} \leq B_{c 2} \\
& \xi_{c I I-2 n} \\
& =C_{\mathrm{cm}} \times\left[\sum_{i=\operatorname{In}\left(N_{1} \cdot(T / \Delta t)\right)+1}^{\operatorname{In}(X / \Delta t)} \int_{0}^{\Delta t} \lambda_{i}(t) d t\right. \\
& +\sum_{j=0}^{N_{3}-1} \sum_{i=\operatorname{In}(j \cdot(T / \Delta t))+(X / \Delta t)+1}^{\operatorname{In}((j+1) \cdot(T / \Delta t))+(X / \Delta t)} \int_{0}^{\Delta t} \lambda_{i}(t) d t \\
& \left.+\sum_{i=\operatorname{In}\left(N_{3} \cdot(T / \Delta t)\right)+(X / \Delta t)+1}^{\operatorname{In}(L / \Delta t)} \int_{0}^{\Delta t} \lambda_{i}(t) d t\right] \\
& +N_{3} \times C_{\mathrm{pm}} \text {, }
\end{aligned}
$$

$$
\begin{aligned}
=C_{\mathrm{cm}} \times & {\left[\sum_{i=\operatorname{In}\left(N_{5} \cdot(T / \Delta t)\right)+(X / \Delta t)+1}^{\operatorname{In}\left(X_{e} / \Delta t\right)} \int_{0}^{\Delta t} \lambda_{i}(t) d t\right.} \\
& +\sum_{j=0}^{N_{6}-1} \sum_{i=\operatorname{In}(j \cdot(T / \Delta t))+\left(X_{e} / \Delta t\right)+1}^{\operatorname{In}((j+1) \cdot(T / \Delta t))+\left(X_{e} / \Delta t\right)} \int_{0}^{\Delta t} \lambda_{i}(t) d t \\
& \left.+\sum_{i=\operatorname{In}\left(N_{6} \cdot(T / \Delta t)\right)+\left(X_{e} / \Delta t\right)+1}^{\operatorname{In}(L / \Delta t)} \int_{0}^{\Delta t} \lambda_{i}(t) d t\right]
\end{aligned}
$$$$
+N_{6} \times C_{\mathrm{pm}}
$$

$$
\begin{aligned}
B_{c 2} & C_{\mathrm{cm}} \times\left[\sum_{i=\operatorname{In}\left(N_{1} \cdot(T / \Delta t)\right)+1}^{\operatorname{In}(X / \Delta t)} \int_{0}^{\Delta t} \lambda_{i}(t) d t\right. \\
& +\sum_{j=0}^{N_{3}-1} \sum_{i=\operatorname{In}(j \cdot(T / \Delta t))+(X / \Delta t)+1}^{\operatorname{In}((j+1) \cdot(T / \Delta t))+(X / \Delta t)} \int_{0}^{\Delta t} \lambda_{i}(t) d t \\
& +\sum_{i=\operatorname{In}\left(N_{3} \cdot(T / \Delta t)\right)+(X / \Delta t)+1}^{\operatorname{In}(L / \Delta t)} \int_{0}^{\Delta t} \lambda_{i}(t) d t \\
& -\sum_{i=\operatorname{In}\left(N_{5} \cdot(T / \Delta t)\right)+(X / \Delta t)+1}^{\operatorname{In}\left(X_{e} / \Delta t\right)} \int_{0}^{\Delta t} \lambda_{i}(t) d t \\
& -\sum_{j=0}^{N_{6}-1} \operatorname{In}((j+1) \cdot(T / \Delta t))+\left(X_{e} / \Delta t\right) \\
& -\sum_{i=\operatorname{In}(j \cdot(T / \Delta t))+\left(X_{e} / \Delta t\right)+1}^{\Delta t} \lambda_{i}(t) d t \\
+ & \left(N_{3}-\operatorname{In}\left(N_{6} \cdot(T / \Delta t)\right)+\left(X_{e} / \Delta t\right)+1\right. \\
\left.N_{6}\right) \cdot & \left.\int_{0}^{\Delta t} \lambda_{i}(t) d t\right]
\end{aligned}
$$

3.4. Minimum Price for Selling the Extended Warranty: Lessor Side. The same as lessee side, this subsection determines the minimum price at which the lessor can sell the extended warranty during the leasing periods. We establish, for each maintenance policy, the best situation so that selling the extended warranty period would be winning for the lessor. This best situation is acquired where the total maintenance cost incurred to him during the leasing horizon in the case of selling the extended warranty would be less than what it would cost him in the case in which he does not sell it.

We assume that $\xi_{M P n}$ and $\xi_{M P y}$ are the total maintenance costs acquired to the lessor for maintenance policy $(P)$, respectively, for the case without the extended warranty period $(n)$ and the case with the extended warranty period (y).

(i) Policy I.

(a) Policy I-1. Consider

$$
\begin{gathered}
\xi_{M I-1 y}-\xi_{M X} \leq \xi_{M I-1 n} \\
\longrightarrow \xi_{M X} \geq \xi_{M I-1 y}-\xi_{M I-1 n} \longrightarrow \xi_{M X} \geq A_{M 1} \\
\xi_{M I-1 n}=C_{c m} \times\left[\sum_{i=1}^{\operatorname{In}(X / \Delta t)} \int_{0}^{\Delta t} \lambda_{i}(t) d t\right] \\
\xi_{M I-1 y} \\
=C_{\mathrm{cm}} \times\left[\sum_{i=1}^{\operatorname{In}(X / \Delta t)} \int_{0}^{\Delta t} \lambda_{i}(t) d t\right.
\end{gathered}
$$




$$
\begin{aligned}
& \left.+\sum_{j=0}^{N_{5}-1} \sum_{i=\operatorname{In}(j \cdot(T / \Delta t))+(X / \Delta t)+1}^{\ln ((j+1) \cdot(T / \Delta t))+(X / \Delta t)} \int_{0}^{\Delta t} \lambda_{i}(t) d t\right] \\
+ & C_{\mathrm{pm}} \times N_{5}, \\
A_{M 1}= & C_{\mathrm{cm}} \\
& \times\left[\sum_{j=0}^{N_{5}-1} \sum_{i=\operatorname{In}(j \cdot(T / \Delta t))+(X / \Delta t)+1}^{\operatorname{In}((j+1) \cdot(T / \Delta t))+(X / \Delta t)} \int_{0}^{\Delta t} \lambda_{i}(t) d t\right] \\
+ & C_{\mathrm{pm}} \times N_{5} .
\end{aligned}
$$

(ii) Policy II.

(a) Policy II-1. Consider

$\xi_{M I I-1 y}-\xi_{M X} \leq \xi_{M I I-1 n}$

$$
\longrightarrow \xi_{M X} \geq \xi_{M I I-1 y}-\xi_{M I I-1 n} \longrightarrow \xi_{M X} \geq B_{M 1},
$$

$\xi_{M I I-1 n}$

$$
\begin{aligned}
=C_{\mathrm{cm}} \times & {\left[\sum_{j=0}^{N_{1} \operatorname{In}((j+1) \cdot(T / \Delta t))} \sum_{i=\operatorname{In}(j \cdot(T / \Delta t))+1}^{\Delta t} \int_{0}(t) d t\right.} \\
& \left.+\sum_{i=\operatorname{In}\left(N_{1} \cdot(T / \Delta t)\right)+1}^{\operatorname{In}(X / \Delta t)} \int_{0}^{\Delta t} \lambda_{i}(t) d t\right] \\
& +C_{\mathrm{pm}} \times N_{1},
\end{aligned}
$$

$\xi_{M I I-1 y}$

$$
\begin{aligned}
=C_{\mathrm{cm}} \times & {\left[\sum_{j=0}^{N_{1}} \sum_{i=\operatorname{In}(j \cdot(T / \Delta t))+1}^{\operatorname{In}((j+1) \cdot(T / \Delta t))} \int_{0}^{\Delta t} \lambda_{i}(t) d t\right.} \\
& +\sum_{i=\operatorname{In}\left(N_{1} \cdot(T / \Delta t)\right)+1}^{\operatorname{In}(X / \Delta t)} \int_{0}^{\Delta t} \lambda_{i}(t) d t \\
& \left.+\sum_{i=\operatorname{In}(X / \Delta t)}^{\operatorname{In}\left(X_{e} / \Delta t\right)} \int_{0}^{\Delta t} \lambda_{i}(t) d t\right]+C_{\mathrm{pm}} \times N_{1}, \\
B_{M 1}= & C_{\mathrm{cm}} \times\left[\sum_{i=\operatorname{In}(X / \Delta t)}^{\operatorname{In}\left(X_{e} / \Delta t\right)} \int_{0}^{\Delta t} \lambda_{i}(t) d t\right] .
\end{aligned}
$$

(b) Policy II-2. Consider

$$
\begin{aligned}
& \xi_{M I I-2 y}-\xi_{M X} \leq \xi_{M I I-2 n} \\
& \quad \longrightarrow \xi_{M X} \geq \xi_{M I I-2 y}-\xi_{M I I-2 n} \longrightarrow \xi_{M w} \geq B_{M 2},
\end{aligned}
$$

$$
\begin{aligned}
& \xi_{M I I-2 n} \\
& =C_{\mathrm{cm}} \times\left[\sum_{j=0}^{N_{1}} \sum_{i=\operatorname{In}(j \cdot(T / \Delta t))+1}^{\operatorname{In}((j+1) \cdot(T / \Delta t))} \int_{0}^{\Delta t} \lambda_{i}(t) d t\right. \\
& \left.+\sum_{i=\operatorname{In}\left(N_{1} \cdot(T / \Delta t)\right)+1}^{\operatorname{In}(X / \Delta t)} \int_{0}^{\Delta t} \lambda_{i}(t) d t\right] \\
& +C_{\mathrm{pm}} \times N_{1}, \\
& \xi_{M I I-2 y} \\
& =C_{\mathrm{cm}} \times\left[\sum_{j=0}^{N_{4}} \sum_{i=\operatorname{In}(j \cdot(T / \Delta t))+1}^{\operatorname{In}((j+1) \cdot(T / \Delta t))} \int_{0}^{\Delta t} \lambda_{i}(t) d t\right. \\
& \left.+\sum_{i=\operatorname{In}\left(N_{4} \cdot(T / \Delta t)\right)+1}^{\operatorname{In}\left(X_{e} / \Delta t\right)} \int_{0}^{\Delta t} \lambda_{i}(t) d t\right] \\
& +C_{\mathrm{pm}} \times N_{4}, \\
& B_{M 2} \\
& =C_{\mathrm{cm}} \times\left[\sum_{j=0}^{N_{4}} \sum_{i=\operatorname{In}(j \cdot(T / \Delta t))+1}^{\operatorname{In}((j+1) \cdot(T / \Delta t))} \int_{0}^{\Delta t} \lambda_{i}(t) d t\right. \\
& +\sum_{i=\operatorname{In}\left(N_{4} \cdot(T / \Delta t)\right)+1}^{\operatorname{In}\left(X_{e} / \Delta t\right)} \int_{0}^{\Delta t} \lambda_{i}(t) d t \\
& -\sum_{j=0}^{N_{1}} \sum_{i=\operatorname{In}(j \cdot(T / \Delta t))+1}^{\operatorname{In}((j+1) \cdot(T / \Delta t))} \int_{0}^{\Delta t} \lambda_{i}(t) d t \\
& \left.-\sum_{i=\operatorname{In}\left(N_{1} \cdot(T / \Delta t)\right)+1}^{\operatorname{In}(X / \Delta t)} \int_{0}^{\Delta t} \lambda_{i}(t) d t\right] \\
& +C_{\mathrm{pm}} \times\left(N_{4}-N_{1}\right) .
\end{aligned}
$$

3.5. Win-Win Interval for the Extended Warranty Cost. The existence of win-win interval of the extended warranty cost is determined according to the previous subsections, where we have determined, for each maintenance policy, the maximum additional cost that the lessee must pay and the minimum price at which the lessor can sell the extended warranty. We determine a theoretical sufficient condition under which a win-win interval will exist and with which the maximum buying additional cost for the lessee is greater than the minimum selling price for the lessor.

(i) Policy I-1. Using (14) and (17), the compromise interval for the extended warranty cost exists if

$$
\begin{aligned}
A_{M 1} \leq & A_{c I} \Longrightarrow C_{\mathrm{cm}} \\
& \times\left[\sum_{i=1}^{\operatorname{In}(X / \Delta t)} \int_{0}^{\Delta t} \lambda_{i}(t) d t\right.
\end{aligned}
$$




$$
\begin{gathered}
+\sum_{j=0}^{N_{3}-1} \sum_{i=\operatorname{In}(j \cdot(T / \Delta t))+(X / \Delta t)+1}^{\operatorname{In}((j+1) \cdot(T / \Delta t))+(X / \Delta t)} \int_{0}^{\Delta t} \lambda_{i}(t) d t \\
+\sum_{i=\operatorname{In}\left(N_{3} \cdot(T / \Delta t)\right)+(X / \Delta t)+1}^{\operatorname{In}(L / \Delta t)} \int_{0}^{\Delta t} \lambda_{i}(t) d t \\
-\sum_{i=\operatorname{In}\left(N_{5} \cdot(T / \Delta t)\right)+(X / \Delta t)+1}^{\operatorname{In}\left(X_{e} / \Delta t\right)} \int_{0}^{\Delta t} \lambda_{i}(t) d t \\
-\sum_{j=0}^{N_{6}-1} \sum_{i=\operatorname{In}\left((j \cdot(T / \Delta t))+\left(X_{e} / \Delta t\right)+1\right.}^{\operatorname{In}(j+1) \cdot(T / \Delta t))+\left(X_{e} / \Delta t\right)} \int_{0}^{\Delta t} \lambda_{i}(t) d t \\
-\sum_{i=\operatorname{In}\left(N_{6} \cdot(T / \Delta t)\right)+\left(X_{e} / \Delta t\right)+1}^{\Delta t} \int_{0}^{\Delta t} \lambda_{i}(t) d t \\
+\sum_{j=0}^{N_{5}-1} \operatorname{In}((j+1) \cdot(T / \Delta t))+(X / \Delta t) \\
\left.+\sum_{i=\operatorname{In}(j \cdot(T / \Delta t))+(X / \Delta t)+1}^{\Delta t} \lambda_{0}(t) d t\right]
\end{gathered}
$$

(ii) Policy II-1. Using (15) and (18), the compromise interval for the extended warranty cost exists if

$$
\begin{aligned}
B_{c 1} \geq & B_{M 1} \Longrightarrow C_{\mathrm{cm}} \\
\times & {\left[\sum_{j=0}^{N_{3}-1} \sum_{i=\operatorname{In}(j \cdot(T / \Delta t))+(X / \Delta t)+1}^{\operatorname{In}((j+1) \cdot(T / \Delta t))+(X / \Delta t)} \int_{0}^{\Delta t} \lambda_{i}(t) d t\right.} \\
& +\sum_{i=\operatorname{In}\left(N_{3} \cdot(T / \Delta t)\right)+(X / \Delta t)+1}^{\operatorname{In}(L / \Delta t)} \int_{0}^{\Delta t} \lambda_{i}(t) d t \\
& -2 \times \sum_{i=\operatorname{In}(X / \Delta t)}^{\operatorname{In}\left(X_{e} / \Delta t\right)} \int_{0}^{\Delta t} \lambda_{i}(t) d t \\
& -\sum_{j=0}^{N_{6}-1} \sum_{i=\operatorname{In}(j \cdot(T / \Delta t))+\left(X_{e} / \Delta t\right)+1}^{\operatorname{In}((j+1) \cdot(T / \Delta t))+\left(X_{e} / \Delta t\right)} \int_{0}^{\Delta t} \lambda_{i}(t) d t \\
& \left.-\sum_{i=\operatorname{In}\left(N_{6} \cdot(T / \Delta t)\right)+\left(X_{e} / \Delta t\right)+1}^{\operatorname{In}(L / \Delta t)} \int_{0}^{\Delta t} \lambda_{i}(t) d t\right] \\
+ & C_{\mathrm{pm}} \times\left(N_{3}-N_{6}\right)>0 .
\end{aligned}
$$

(iii) Policy II-2. Using (16) and (19), the compromise interval for the extended warranty cost exists if

$$
\begin{aligned}
& B_{c 2} \geq B_{M 2} \Longrightarrow C_{c m} \\
& \times\left[\sum_{i=\operatorname{In}\left(N_{1} \cdot(T / \Delta t)\right)+1}^{\operatorname{In}(X / \Delta t)} \int_{0}^{\Delta t} \lambda_{i}(t) d t\right. \\
& +\sum_{j=0}^{N_{3}-1} \sum_{i=\operatorname{In}(j \cdot(T / \Delta t))+(X / \Delta t)+1}^{\operatorname{In}((j+1) \cdot(T / \Delta t))+(X / \Delta t)} \int_{0}^{\Delta t} \lambda_{i}(t) d t \\
& +\sum_{i=\operatorname{In}\left(N_{3} \cdot(T / \Delta t)\right)+(X / \Delta t)+1}^{\operatorname{In}(L / \Delta t)} \int_{0}^{\Delta t} \lambda_{i}(t) d t \\
& -\sum_{i=\operatorname{In}\left(N_{5} \cdot(T / \Delta t)\right)+(X / \Delta t)+1}^{\operatorname{In}\left(X_{e} / \Delta t\right)} \int_{0}^{\Delta t} \lambda_{i}(t) d t \\
& -\sum_{j=0}^{N_{6}-1} \sum_{i=\operatorname{In}(j \cdot(T / \Delta t))+\left(X_{e} / \Delta t\right)+1}^{\operatorname{In}((j+1) \cdot(T / \Delta t))+\left(X_{e} / \Delta t\right)} \int_{0}^{\Delta t} \lambda_{i}(t) d t \\
& -\sum_{i=\operatorname{In}\left(N_{6} \cdot(T / \Delta t)\right)+\left(X_{e} / \Delta t\right)+1}^{\operatorname{In}(L / \Delta t)} \int_{0}^{\Delta t} \lambda_{i}(t) d t \\
& -\sum_{j=0}^{N_{4}} \sum_{i=\operatorname{In}(j \cdot(T / \Delta t))+1}^{\operatorname{In}((j+1) \cdot(T / \Delta t))} \int_{0}^{\Delta t} \lambda_{i}(t) d t \\
& -\sum_{i=\operatorname{In}\left(N_{4} \cdot(T / \Delta t)\right)+1}^{\operatorname{In}\left(X_{e} / \Delta t\right)} \int_{0}^{\Delta t} \lambda_{i}(t) d t \\
& +\sum_{j=0}^{N_{1}} \sum_{i=\operatorname{In}(j \cdot(T / \Delta t))+1}^{\operatorname{In}((j+1) \cdot(T / \Delta t))} \int_{0}^{\Delta t} \lambda_{i}(t) d t \\
& \left.+\sum_{i=\operatorname{In}\left(N_{1} \cdot(T / \Delta t)\right)+1}^{\operatorname{In}(X / \Delta t)} \int_{0}^{\Delta t} \lambda_{i}(t) d t\right] \\
& +C_{\mathrm{pm}} \times\left(N_{3}-N_{6}-N_{4}+N_{1}\right)>0 \text {. }
\end{aligned}
$$

\section{Numerical Example}

In order to illustrate the model developed previously, we consider a forecasting production/maintenance problem for a company represented by a leasing machine which has to satisfy a stochastic demand assumed Gaussian, under service level, over a finite leasing horizon. The number $L$ of leasing periods $\Delta t$ is equal to 24 , with $\Delta t=1 \mathrm{um}$. The leasing machine has a degradation law characterized by a Weibull distribution with shape parameter $\alpha$ and scale parameter $\beta$ (with these two parameters, the degradation is linear $\gamma=2$ ). From the failure rate equation, we determined the average number of failures 
TABLE 1

\begin{tabular}{lcccc}
\hline$d_{1}$ & $d_{2}$ & $d_{3}$ & $d_{4}$ & $d_{5}$ \\
\hline 15 & 17 & 15 & 15 & 15 \\
\hline$d_{6}$ & $d_{7}$ & $d_{8}$ & $d_{9}$ & $d_{10}$ \\
\hline 14 & 16 & 14 & 16 & 13 \\
\hline$d_{11}$ & $d_{12}$ & $d_{13}$ & $d_{14}$ & $d_{15}$ \\
\hline 15 & 14 & 15 & 12 & 15 \\
\hline$d_{16}$ & $d_{17}$ & $d_{18}$ & $d_{19}$ & $d_{20}$ \\
\hline 13 & 15 & 11 & 16 & 13 \\
\hline$d_{21}$ & $d_{22}$ & $d_{23}$ & $d_{24}$ & $d_{25}$ \\
\hline 15 & 12 & 14 & 16 & 14 \\
\hline
\end{tabular}

TABLE 2

\begin{tabular}{lcccc}
\hline$u^{*}(1)$ & $u^{*}(2)$ & $u^{*}(3)$ & $u^{*}(4)$ & $u^{*}(5)$ \\
\hline 9 & 14 & 8 & 12 & 12 \\
\hline$u^{*}(6)$ & $u^{*}(7)$ & $u^{*}(8)$ & $u^{*}(9)$ & $u^{*}(10)$ \\
\hline 15 & 9 & 13 & 14 & 11 \\
\hline$u^{*}(11)$ & $u^{*}(12)$ & $u^{*}(13)$ & $u^{*}(14)$ & $u^{*}(15)$ \\
\hline 10 & 5 & 11 & 12 & 5 \\
\hline$u^{*}(16)$ & $u^{*}(17)$ & $u^{*}(18)$ & $u^{*}(19)$ & $u^{*}(20)$ \\
\hline 15 & 16 & 12 & 10 & 6 \\
\hline$u^{*}(21)$ & $u^{*}(22)$ & $u^{*}(23)$ & $u^{*}(24)$ & $u^{*}(25)$ \\
\hline 2 & 5 & 17 & 3 & 14 \\
\hline
\end{tabular}

assuming that after each preventive maintenance action the equipment is in state "as good as new."

The following arbitrarily chosen input data are also considered:

$$
\begin{aligned}
& C_{\mathrm{pr} 1}=3 \mathrm{mu}, C_{\mathrm{pr} 2}=10 \mathrm{mu} \text {, service level } \alpha=0.95, \\
& C_{s}=5 \mathrm{mu}, \text { initial inventory } S_{0}=20 \text {, the variance of } \\
& \text { demand } V_{d_{k}}=1.21, X=2, X_{e}=6, C_{\mathrm{cm}}=1500 \text {, and } \\
& C_{\mathrm{pm}}=200 .
\end{aligned}
$$

To compute the failure rate, we assume that the nominal degradation follows a Weibull distribution given by

$$
\lambda_{n}(t)=\frac{\gamma}{\beta} \cdot\left(\frac{t}{\beta}\right)^{\gamma-1}
$$

The average of forecasting demand is presented in Table 1.

Applying our analytical model, we used the numerical algorithms for constrained global optimization with MATHEMATICA, in order to realize this optimization. Firstly, we are interested to find the forecasting optimal production plan, which is presented in Table 2. According to the production plan obtained, we have observed, for each maintenance policy, the optimal preventive maintenance interval $T^{*}$ and the existence of a win-win interval where lower and upper boundaries are, respectively, the minimum price at which the lessor should sell the extended warranty and the maximum additional cost that the lessee should pay for the extended warranty.

The forecasting production plan is presented in Table 2.

From Table 3, we canunderstand, for example, that, for Policy II-2 (preventive maintenance performed during $\left.\left[0, X_{e}\right)\right)$, the optimal preventive maintenance interval for lessor is equal to $T_{M}^{*}=3$ and for the lessee is equal to $T_{C}^{*}=2$, and the win-win interval for the extended warranty cost existed between 202.25 and $203.476 \mathrm{mn}$ units (Figure 5) which characterizes the threshold values, respectively, for the lessor and the lessee. In this case, the best compromise corresponds to the middle of this interval with an extended warranty cost of $202.863 \mathrm{mn}$ units.

In fact, from the lessor side, as preventive maintenance actions become more efficient, the average number of failures gets lower. Consequently, he would pay less for minimal repairs and therefore his threshold value for the extended warranty cost becomes lower. From the lessor side, taking the extended warranty will result in having the leasing machine entering the postwarranty period with a higher reliability, thanks to preventive maintenance actions performed during $\left[X, X_{e}\right]$. Consequently, the lessee is willing to pay more for the extended warranty whereas preventive maintenance becomes more efficient giving a higher reliability and minimal average number of failures and hence least minimal repairs during the postwarranty period.

As another example, for Policy II-1, since the period during which PM is performed is related only to the basic warranty period, the win-win interval for the extended warranty cost is found between 3.41471 and 200.238; since there is no preventive maintenance for lessor side, the expected number of minimal repairs during this period remains obviously the same with or without the extended warranty whereas on the lessee side the optimal preventive maintenance interval is equal to $T_{c}^{*}=3$.

Also, from Figure 6, we can notice, for Policy I-1, that choosing an extended warranty period would be interesting neither for the lessee nor for the lessor. The win-win interval does not exist because the minimum price at which the lessor should sell the extended warranty (equal to 202.347) is greater than the maximum additional cost that the lessee should pay for the extended warranty (equal to 194,706). The extended warranty would not be as advantageous for the lessor as for the lessee due to the fact that since there is no preventive maintenance, the average number of failures during $\left[X, X_{e}\right]$ remains obviously the same with or without the extended warranty.

For $C_{p m}=200$ and $C_{c m}=1500$. For compromise intervals for the extended warranty cost see Table 3 .

Variation of PM and CM Costs. We identify the impact of varying the maintenance preventive cost $\left(C_{\mathrm{pm}}\right)$ and the maintenance corrective cost $\left(C_{\mathrm{cm}}\right)$ during the leasing horizon. Besides the nominal values $\left(C_{\mathrm{pm}}=200, C_{\mathrm{cm}}=1500\right)$, we consider a higher value $\left(C_{\mathrm{pm}} \in\{300,400,600\} ; C_{\mathrm{cm}} \in\right.$ $\{1700,1900,2000\})$. Obviously, the effect of varying the maintenance costs can be observed for different policies. Certainly, for these different policies, we note that the period over which preventive maintenance is performed has a direct impact on the average number of failures and on the number of minimal repairs during the extended warranty period $\left[X, X_{e}\right]$.

We can look at Tables 4 and 5 that for Policy I-1 (preventive maintenance actions are performed during $\left[X_{e}, L\right)$ the 
TABLE 3

\begin{tabular}{|c|c|c|c|c|c|c|c|}
\hline \multirow{2}{*}{$T$} & \multicolumn{3}{|c|}{ Policy I-1 } & \multicolumn{2}{|c|}{ Policy II-1 } & \multicolumn{2}{|c|}{ Policy II-2 } \\
\hline & Lessor & & Lessee & Lessor & Lessee & Lessor & Lessee \\
\hline 1 & 803.724 & & 804.288 & 3.41471 & 800.309 & 803.194 & 803.194 \\
\hline 2 & 403.72 & & 404.288 & 3.41471 & 400.309 & 403.194 & 203.476 \\
\hline 3 & 202.347 & $\emptyset$ & 194.706 & 3.41471 & 200.238 & 202.25 & 403.759 \\
\hline 4 & 203.724 & & 204.288 & 3.41471 & 200.309 & 203.759 & 403.194 \\
\hline
\end{tabular}

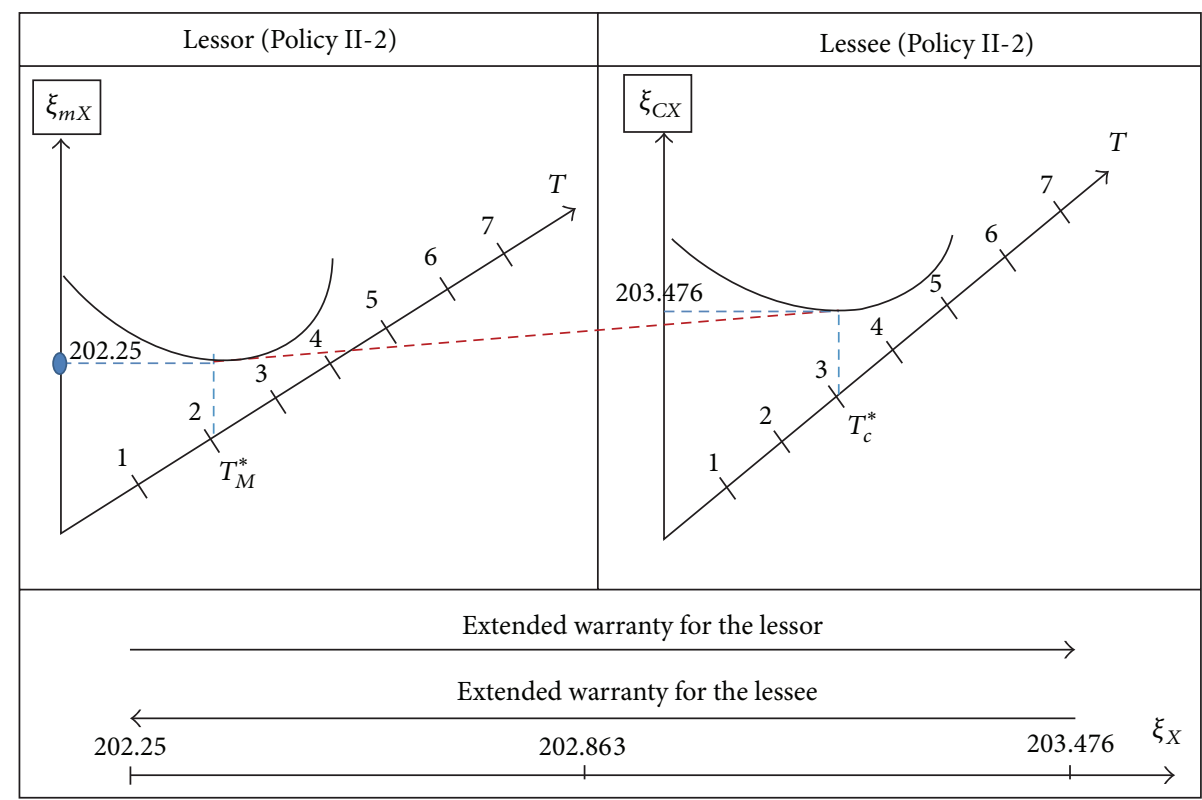

FIGURE 5: Win-win interval for the extended warranty for option II-2.

$\stackrel{\text { Extended warranty for the lessee }}{\longleftarrow} \underset{194.706}{\stackrel{202.347}{\longleftrightarrow}} \stackrel{\text { Extended warranty for the lessor }}{\longleftrightarrow} \xi_{X}$

FIGURE 6: Absence of a win-win interval for the extended warranty cost for Policy I-1.

preventive maintenance interval is increased if the preventive and corrective costs are increased but it is beneficial for neither the lessee nor the lessor to adopt the extended warranty period whatever the maintenance costs are. This can be explained by the fact that, at the end of warranty period $X_{e}$, it would be too late to start preventive maintenance action and the degradation of leasing machine increased and the preventive maintenance action cannot improve the reliability of leasing machine even if they are performed more frequently during $\left[X_{e}, L\right]$.

For Policies II-1 (preventive maintenance performed during $[0, X)$ ) and II-2 (preventive maintenance carried out during $\left[0, X_{e}\right)$ ), we can remark differing trend compared to Policy I-1, since the win-win intervals exist for any values of $C_{\mathrm{pm}}$ and $C_{\mathrm{cm}}$. These intervals become larger as the maintenance costs increase but for Policy II-1, the minimum price at which the lessor should sell the extended warranty is fixed for any values of $C_{\mathrm{pm}}$ and $C_{\mathrm{cm}}$; since there is no preventive maintenance for the lessor side, the expected number of minimal repairs during this period remains obviously the same with or without the extended warranty.

$C_{c m}=1500$. See Table 4.

$C_{p m}=200$. See Table 5 .

Effects of the Variation of Production Period Length $\Delta t$. In this section, we investigate the effects of varying the periodicity length $(\Delta t)$ of production during the product's life cycle. Beside the nominal value $(\Delta t=1 \mathrm{um})$, we consider a higher value $(\Delta t=2)$.

Obviously, the effect of varying production period can only be observed for Policy II-1 and Policy II-2. The optimal preventive maintenance interval for lessor is decreased for production period $\Delta t=2$ (Policy II-1: $T_{M}^{*}=2$ and $T_{C}^{*}=2$ ) (Table 6) with a higher cost relative to $\Delta t=1$ (Policy II-1: $T_{M}^{*}=3$ and $T_{C}^{*}=3$ ) (Table 3 ). The compromise interval for the extended warranty cost gets larger as the number of PM actions increases (production period increasing). In fact, if the production period length or the demand increases, the principal machine produces more to meet the customers' demands; thus the machine will undergo more failures and the preventive maintenance interval increases. According to 
TABLE 4

\begin{tabular}{cccccccr}
\hline \multirow{2}{*}{$C_{\mathrm{pm}}$} & \multicolumn{2}{c}{ Policy I-1 } & \multicolumn{2}{c}{ Policy II-1 } & \multicolumn{2}{c}{ Policy II-2 } \\
& Lessor & & Lessee & Lessor & Lessee & Lessor & 202.25 \\
200 & 202,347 & $\emptyset$ & 194,706 & 3.41471 & 200.238 & 303.476 \\
300 & 302,34 & $\emptyset$ & 294,706 & 3,41471 & 300,238 & 303,282 \\
400 & 402,34 & $\emptyset$ & 394,706 & 3,41471 & 400,238 & 400,282 & 403,759 \\
600 & 602,347 & $\emptyset$ & 594,706 & 3,41471 & 600,238 & 600,282 & 603,759 \\
\hline
\end{tabular}

the previous results presented through the variability of $\Delta t$, the production period length is really impacted visibly.

For $C_{p m}=200$ and $C_{c m}=1500$ and $\Delta t=2$. For compromise intervals for the extended warranty cost, see Table 6 .

\section{Conclusion}

This paper treats a forecasting production/maintenance problem correlated to the adoption of an extended warranty period for a leasing machine during a finite leasing horizon. Firstly, we have developed a mathematical model for a forecasting problem in order to determine a forecasting production plan. Secondly, an analytical model has been proposed in order to present a study of the opportunity provided by the extended warranty in leasing contract from both the lessee and the lessor. We proposed different maintenance policies during the finite leasing horizon, which we have considered to be the influence of production rates on the degradation degree of leasing machine and including periodic preventive maintenance actions with different costs. For each maintenance policy, we expressed the total cost incurred by the lessee and by the lessor in order to determine the maximum additional cost the lessee should pay for the extended warranty and the minimum price at which the lessor should sell it. For each policy and for any given situation, conditions of existence of a win-win interval between the lessee and the lessor have resulted.

For future research, we will consider a more complex system with other types of warranty policies (including the number of warranty dimensions, the renewability of a warranty, and the warranty compensation methods). Concerning the maintenance strategy, we will consider new hypotheses: the corrective and preventive times are not negligible.

\section{Appendix}

Proof of (5). The inventory variable $S_{k}$ is statistically described by its mean $E\left\{S_{k}\right\}=\widehat{S}_{k}$ and variance

$$
E\left\{\left(S_{k}-\widehat{S}_{k}\right)^{2}\right\}=\operatorname{Var}\left(S_{k}\right)
$$

The expected inventory cost is

$$
C_{s} \cdot E\left\{S_{k}^{2}\right\}=C_{s} \cdot \widehat{S}_{k}^{2}
$$

Balance equation (2) $S_{k+1}=S_{k}+U_{k}-d_{k} k \in\{0,1, \ldots, L-$ $1\}$ can be converted into an equivalent inventory balance equation, as follows:

$$
\begin{aligned}
(2) & \Longrightarrow E\left\{S_{k+1}\right\}=E\left\{S_{k}\right\}+U_{k}-d_{k} \\
\Longrightarrow & \widehat{S}_{k+1}=\widehat{S}_{k}+U_{k}-\widehat{d}_{k} .
\end{aligned}
$$

Equation (A.3) represents the mean variation of inventory at each period $k, k \in\{1,2, \ldots, N-1\}$. Furthermore, $u_{i, k}$ is deterministic, since it does not depend on the random variables $d_{k}$ and $S_{k}$. That is, $E\{U\}=U_{k}$ with $V\left(U_{k}\right)=$ 0 for all $k$. Taking the difference between (2) and (A.3)

$$
\begin{aligned}
S_{k+1} & -\widehat{S}_{k+1}=S_{k}-\widehat{S}_{k}-\left(d_{k}-\widehat{d}_{k}\right) \\
& \Longrightarrow \\
\Longrightarrow & \left(S_{k+1}-\widehat{S}_{k+1}\right)^{2}=\left(\left(S_{k}-\widehat{S}_{k}\right)-\left(d_{k}-\widehat{d}_{k}\right)\right)^{2} \\
\Longrightarrow & E\left(\left(S_{k+1}-\widehat{S}_{k+1}\right)^{2}\right) \\
= & E\left(\left(S_{k}-\widehat{S}_{k}\right)-\left(d_{k}-\widehat{d}_{k}\right)^{2}\right) \\
\Longrightarrow & E\left(\left(S_{k+1}-\widehat{S}_{k+1}\right)^{2}\right) \\
= & E\left(\left(S_{k}-\widehat{S}_{k}\right)^{2}+\left(d_{k}-\widehat{d}_{k}\right)^{2}-2 \cdot\left(S_{k}-\widehat{S}_{k}\right) \cdot\left(d_{k}-\widehat{d}_{k}\right)\right) \\
\Longrightarrow & E\left(\left(S_{k+1}-\widehat{S}_{k+1}\right)^{2}\right) \\
= & E\left(\left(S_{k}-\widehat{S}_{k}\right)^{2}\right)+E\left(\left(d_{k}-\widehat{d}_{k}\right)^{2}\right) \\
& -2 \cdot E\left(\left(S_{k}-\widehat{S}_{k}\right) \cdot\left(d_{k}-\widehat{d}_{k}\right)\right) .
\end{aligned}
$$

Since $S_{k}$ and $d_{k}$ are independent random variables we can deduce that

$$
E\left(\left(S_{k}-\widehat{S}_{k}\right) \cdot\left(d_{k}-\widehat{d}_{k}\right)\right)=E\left(\left(S_{k}-\widehat{S}_{k}\right)\right) \cdot E\left(\left(d_{k}-\widehat{d}_{k}\right)\right)
$$

Also, it is easy to see that

$$
\begin{aligned}
& E\left(\left(S_{k}-\widehat{S}_{k}\right)\right)=E\left(S_{k}\right)-E\left(\widehat{S}_{k}\right)=0, \\
& E\left(\left(d_{k}-\widehat{d}_{k}\right)\right)=E\left(d_{k}\right)-E\left(\widehat{d}_{k}\right)=0 .
\end{aligned}
$$


TABLE 5

\begin{tabular}{cccccccc}
\hline \multirow{2}{*}{$C_{\mathrm{cm}}$} & & Policy I-1 & \multicolumn{2}{c}{ Policy II-1 } & \multicolumn{2}{c}{ Policy II-2 } & Lessor \\
\hline 1500 & Lessor & & Lessee & Lessor & Lessee & 200.238 & 200.282 \\
1700 & 202.34 & $\emptyset$ & 192.915 & 4.55294 & 200.27 & 200.32 \\
1900 & 202.66 & $\emptyset$ & 191.97 & 4.55294 & 200.302 & 200.358 \\
2000 & 202,973 & $\emptyset$ & 191,025 & 4.55294 & 204.26 \\
\hline
\end{tabular}

TABLE 6

\begin{tabular}{|c|c|c|c|c|c|c|c|}
\hline \multirow{2}{*}{$T$} & \multicolumn{3}{|c|}{ Policy I-1 } & \multicolumn{2}{|c|}{ Policy II-1 } & \multicolumn{2}{|c|}{ Policy II-2 } \\
\hline & Lessor & & Lessee & Lessor & Lessee & Lessor & Lessee \\
\hline 1 & 903,830 & & 904,180 & 3.41471 & 800.309 & 803.194 & 803.194 \\
\hline 2 & 303,27 & $\emptyset$ & 305,28 & 4.7141 & 500.39 & 504.194 & 504.76 \\
\hline 3 & 345,347 & & 304,706 & 4.91471 & 501.238 & 522.25 & 503.759 \\
\hline 4 & 360,724 & & 306,288 & 4.94417 & 511.309 & 533.759 & 513.140 \\
\hline
\end{tabular}

Consequently,

$$
\begin{aligned}
E\left(\left(S_{k+1}-\widehat{S}_{k+1}\right)^{2}\right) & =E\left(\left(S_{k}-\widehat{S}_{k}\right)^{2}\right)+E\left(\left(d_{k}-\widehat{d}_{k}\right)^{2}\right) \\
& \Longrightarrow\left(\sigma_{s_{k+1}}\right)^{2}=\left(\sigma_{s_{k}}\right)^{2}+\left(\sigma_{d_{k}}\right)^{2} .
\end{aligned}
$$

If we assume that $\sigma_{s}(0)=0$ and $\sigma_{d k}$ is constant and equal to $\sigma_{d}$ for all $k$ 's, we can deduce that

$$
\begin{aligned}
\left(\sigma_{s_{k}}\right)^{2} & =k \cdot\left(\sigma_{d}\right)^{2} \\
& \Longrightarrow E\left(S_{k}^{2}\right)-\widehat{S}_{k}^{2}=k \cdot\left(\sigma_{d}\right)^{2} \\
& \Longrightarrow E\left(S_{k}^{2}\right)=k \cdot\left(\sigma_{d}\right)^{2}+\widehat{S}_{k}^{2} .
\end{aligned}
$$

Substituting (A.3) in the expected cost (1)

$$
\begin{gathered}
Z=C_{s} \cdot E\left(S_{L}^{2}\right)+\sum_{i=0}^{L} C_{s} \cdot E\left(S_{k}^{2}\right)+C_{\mathrm{pr}} \cdot U_{k}^{2}, \\
Z(u)=C_{s} \times\left(\hat{S}_{L}^{2}\right)+\sum_{k=0}^{L-1} C_{s} \cdot \hat{S}_{k}^{2}+C_{\mathrm{pr}} \times u_{k}^{2}+C_{s} \times\left(\sigma_{d}\right)^{2} \times \sum_{i=0}^{L} k, \\
Z(u)=C_{s} \times\left(\hat{S}_{L}^{2}\right)+\sum_{k=0}^{L-1} C_{s} \cdot \hat{S}_{k}^{2}+C_{\mathrm{pr}} \times u_{k}^{2}+C_{s} \times \sigma_{d}^{2} \\
\times \frac{L(L+1)}{2} .
\end{gathered}
$$

Proof of (8). Consider

$$
\begin{aligned}
& S(k+1)=S(k)+U(k)-d(k) \\
& \quad \Longrightarrow \operatorname{Prob}(S(k+1) \geq 0) \geq \alpha \\
& \Longrightarrow \operatorname{Prob}(S(k)+U(k)-d(k) \geq 0) \geq \alpha \\
& \Longrightarrow \operatorname{Prob}(S(k)+U(k) \geq d(k)) \geq \alpha \\
& \Longrightarrow \operatorname{Prob}(S(k)+U(k)-\widehat{d}(k) \geq d(k)-\widehat{d}(k)) \geq \alpha \\
& \Longrightarrow \operatorname{Prob}\left(\frac{S(k)+U(k)-\widehat{d}(k)}{V_{d, k}} \geq \frac{d(k)-\widehat{d}(k)}{V_{d, k}}\right) \geq \alpha
\end{aligned}
$$

with $\widehat{d}(k)$ average demand at period $k$ and $\operatorname{Var}(d(k))=V_{d, k} \geq$ 0 variance of demand $d$ at period $k$.

This equation is in the form of $\operatorname{Prob}[Y \geq X] \geq \alpha$, with $X=\left(\left(d_{k}-\widehat{d}_{k}\right) / V_{d_{k}}\right)$ being a Gaussian random variable representing the demand $d_{k}$, and $\varphi_{d_{k}}$ is a cumulative Gaussian distribution function of the form $F(Y) \geq \alpha$ such as

$$
\Longrightarrow \varphi_{d, k}\left(\frac{S(k)+U(k)-\widehat{d}(k)}{V_{d, k}}\right) \geq \alpha .
$$

Since $\lim _{d_{k} \rightarrow-\infty} \varphi_{d_{k}}=0$ and $\lim _{d_{k} \rightarrow+\infty} \varphi_{d_{k}}=1$, the function $\varphi_{d_{k}}$ is strictly increasing, and we note that it is indefinitely differentiable. That is why we conclude that $\varphi_{d_{k}}$ is invertible.

Thus,

$$
\begin{aligned}
& \frac{S(k)+U(k)-\widehat{d}(k)}{V_{d, k}} \geq \varphi_{d, k}^{-1}(\alpha) \\
& \Longrightarrow S(k)+U(k)-\widehat{d}(k) \geq V_{d, k} \cdot \varphi_{d, k}^{-1}(\alpha) \\
& \Longrightarrow U(k) \geq V_{d, k} \cdot \varphi_{d, k}^{-1}(\alpha)+\widehat{d}(k)-S(k) .
\end{aligned}
$$




\section{Notation}

$\Delta t: \quad$ Length of a production period

$L$ : $\quad$ Number of leasing periods

$X: \quad$ Warranty periods

$X_{e}$ : Warranty period including both basic period $X$ and extension

$U_{k}$ : Production rate by machine $M$ during period $k(k=0,1, \ldots, L)$

$\widehat{d}(k)$ : Average demand during period $k$ $(k=0,1, \ldots, L)$

$V_{d(k)}$ : Variance of demand during period $k$ $(k=0,1, \ldots, L)$

$S_{k}$ : Inventory level of $S$ at the end of period $k$ $(k=0,1, \ldots, L)$

$\widehat{S}_{k}: \quad$ Average inventory level of $S$ during period $k(k=0,1, \ldots, L)$

$C_{\mathrm{pr}}$ : Unit production cost of leasing machine

$C_{s}$ : Holding cost of product unit during one period

mu: Monetary unit

$U^{\max }$ : Maximal production rate of leasing machine

$U^{\text {min }}$ : Minimal production rate of leasing machine

$\alpha$ : $\quad$ Probability index related to customer satisfaction and expressing the service level

$S_{0}$ : Initial inventory

$C_{\mathrm{pm}}$ : Preventive maintenance cost

$C_{\mathrm{cm}}$ : Corrective maintenance cost.

\section{Conflict of Interests}

The authors declare that there is no conflict of interests regarding the publication of this paper.

\section{References}

[1] D. N. P. Murthy and E. Asgharizadeh, "Optimal decision making in a maintenance service operation," European Journal of Operational Research, vol. 116, no. 2, pp. 259-273, 1999.

[2] R. H. Yeh and W. L. Chang, "Optimal threshold value of failurerate for leased products with preventive maintenance actions," Mathematical and Computer Modelling, vol. 46, no. 5-6, pp. 730737, 2007.

[3] J. Jaturonnatee, D. N. P. Murthy, and R. Boondiskulchok, "Optimal preventive maintenance of leased equipment with corrective minimal repairs," European Journal of Operational Research, vol. 174, no. 1, pp. 201-215, 2006.

[4] T. M. Berke and N. Zaino, "Warranties: What are they? What do they really cost?" in Proceedings of the Annual Reliability and Maintainability Symposium, pp. 326-330, January 1991.

[5] C. S. Kim, I. Djamaludin, and D. N. P. Murthy, "Warranty and discrete preventive maintenance," Reliability Engineering and System Safety, vol. 84, no. 3, pp. 301-309, 2004.

[6] W. Y. Yun, D. N. P. Murthy, and N. Jack, "Warranty servicing with imperfect repair," International Journal of Production Economics, vol. 111, no. 1, pp. 159-169, 2008.
[7] Y.-H. Chien, "Optimal age-replacement policy under an imperfect renewing free-replacement warranty," IEEE Transactions on Reliability, vol. 57, no. 1, pp. 125-133, 2008.

[8] Y.-H. Chien, "Optimal age for preventive replacement under a combined fully renewable free replacement with a pro-rata warranty," International Journal of Production Economics, vol. 124, no. 1, pp. 198-205, 2010.

[9] S. Bouguerra, A. Chelbi, and N. Rezg, "A decision model for adopting an extended warranty under different maintenance policies," International Journal of Production Economics, vol. 135, no. 2, pp. 840-849, 2012.

[10] S. Wu and P. Longhurst, "Optimising age-replacement and extended non-renewing warranty policies in lifecycle costing," International Journal of Production Economics, vol. 130, no. 2, pp. 262-267, 2011.

[11] Z. Hajej, N. Rezg, and A. Gharbi, "Integrated maintenance policy optimization under lease/warranty contract," in Proceedings of the International Conference on Industrial Engineering (ICIE '13), Dubai, UAE, October 2013.

[12] H. Zied, D. Sofiene, and R. Nidhal, "Optimal integrated maintenance/production policy for randomly failing systems with variable failure rate," International Journal of Production Research, vol. 49, no. 19, pp. 5695-5712, 2011. 


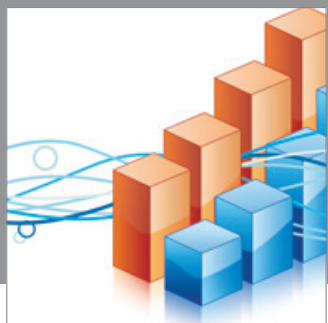

Advances in

Operations Research

mansans

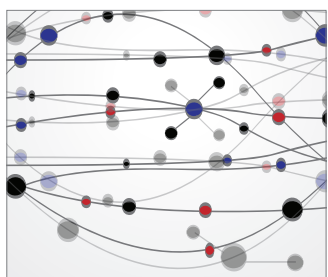

The Scientific World Journal
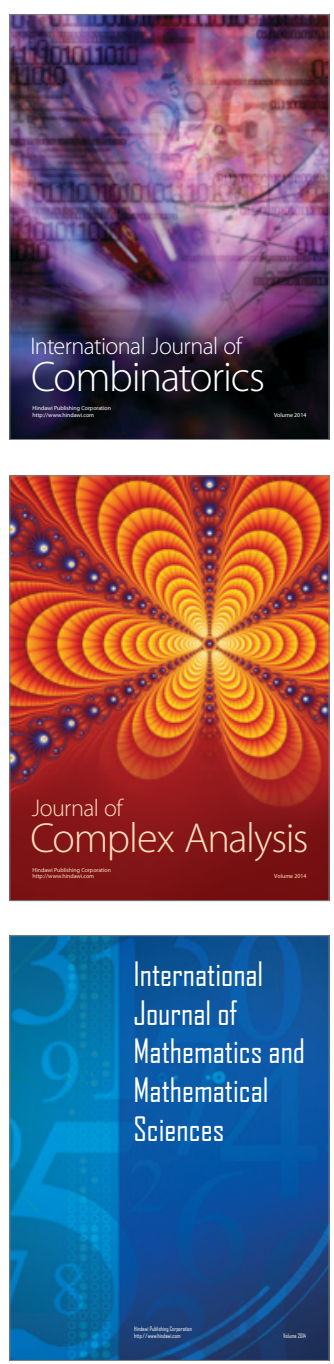
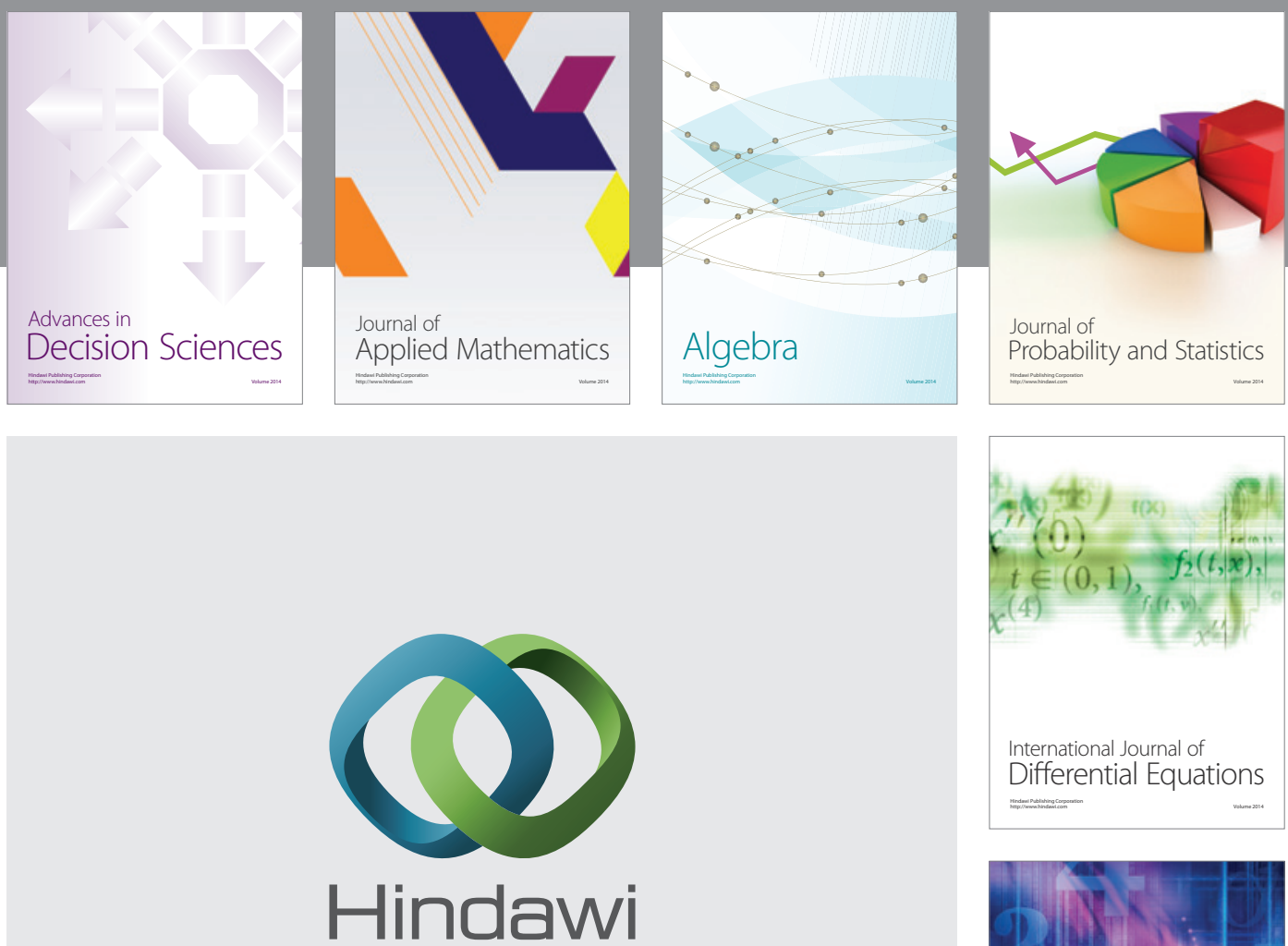

Submit your manuscripts at http://www.hindawi.com
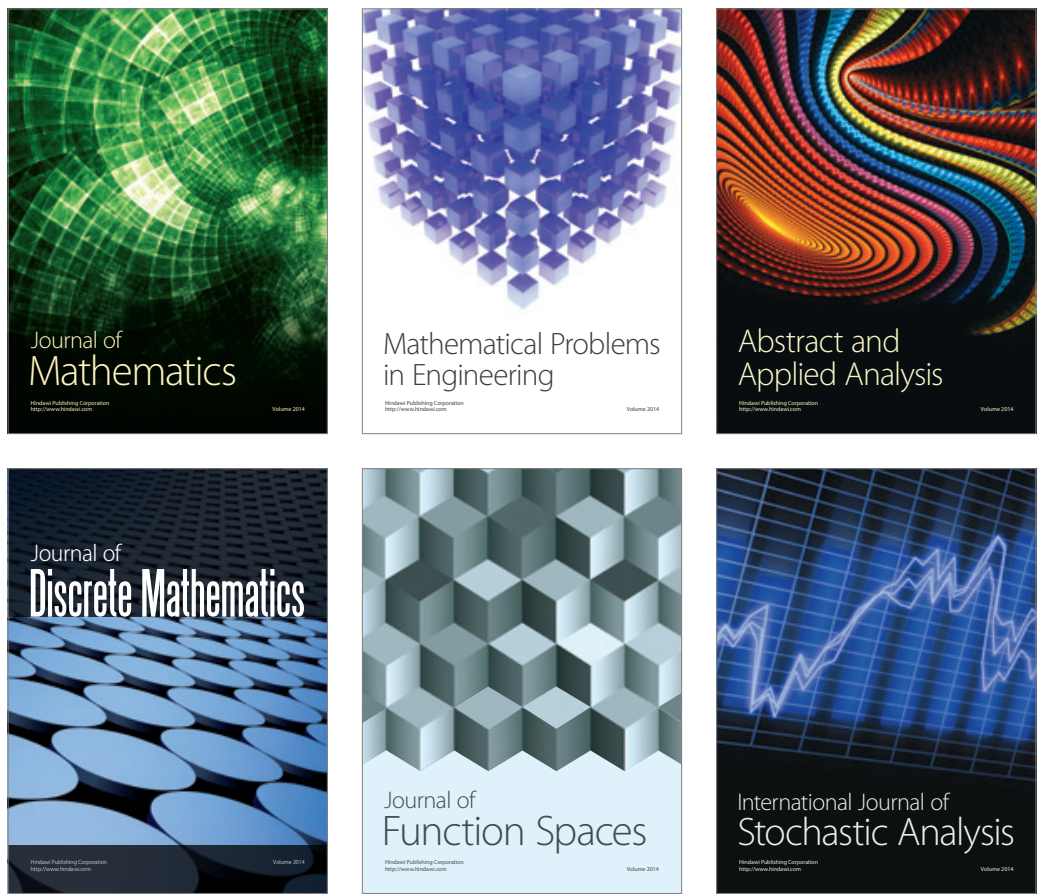

Journal of

Function Spaces

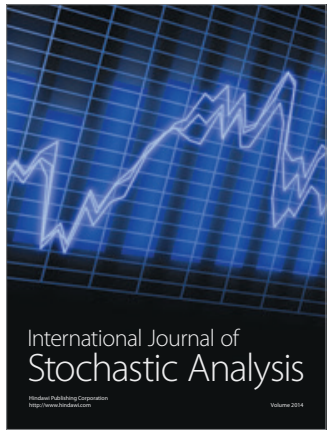

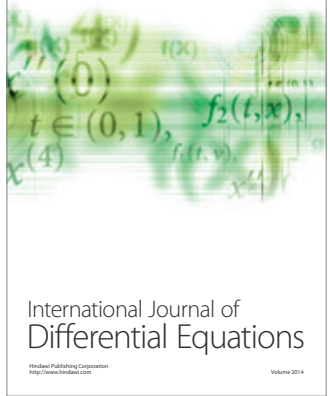
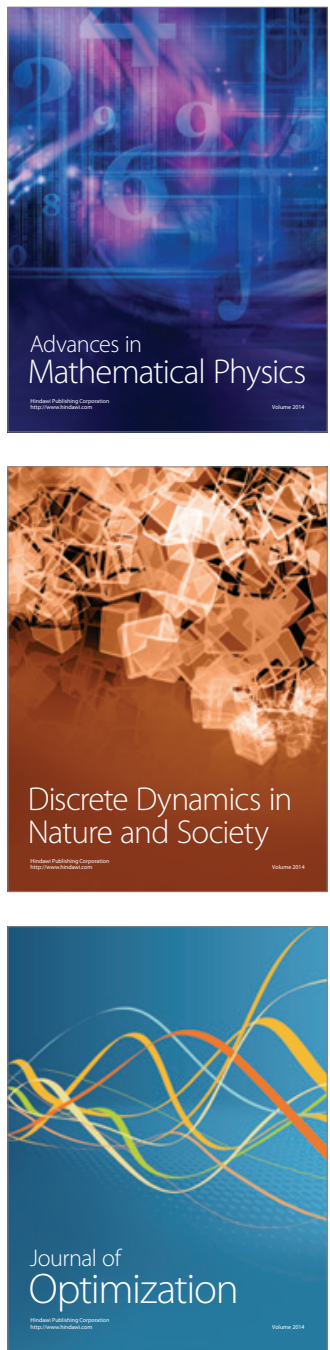